\title{
The Study of Factors Restricting the Translator's Initiative
}

\author{
Xiang-Xin LIU
}

Department of Public Relations, Wuhan Railway Vocational Technological University, Wuhan, 430325, China

Keywords: The translator's initiative, Subjective factors, Objective factors.

\begin{abstract}
Though studies about the translator's initiative in China claimed to have a long history and the importance of the translator's initiative has been discussed frequently both abroad and at home, systematic studies about the translator's initiative are inadequate and sporadic. There is a need to study the translator's initiative and sort out the factors restricting the translator.
\end{abstract}

\section{Introduction}

The existence of the translator's initiative is inevitable. During the translation, the source text is placed in an unexpected environment, and the translator wants to restore the source text as much as possible, but on purpose or not, some original thoughts of the writer are changed because of a series of subjective and objective factors that restrict the translator, including the translator's life experience, the translation thoughts of the translator, the translator's ability, the source text, culture, readers' expectation, the sponsor, the social dominating ideology and so on. The new work will display, strengthen and explain what are understood and accepted by the translator .

As we know, the translator wants to use his initiative to surpass the source text, but at the same time, the initiative is limited by the source text and other factors. Translators should keep the restricting factors in mind, so that his work will reach a wider range of readers and adapt to the new cultural, political and economic environment.

Though studies about the translator's initiative in China claimed to have a long history and the importance of the initiative of the translator has been discussed frequently both abroad and at home, systematic studies about the translator's initiative are inadequate and sporadic. There is a need to study the translator's initiative and sort out the factors restricting the translator.

\section{About the Translator's Initiative}

In traditional translation theory, the task of the translator is to faithfully reproduce the source text as much as possible. Therefore, the translator should avoid initiative. But the existence of the translator's initiative is inevitable. The translator is a person with positive thinking, rather than a language decoding machine or a coolie with a good dictionary. During the translation, the source text is placed in an unexpected environment, the original intention of the translator in his translation is to restore the source text as much as possible, but as a result of the existence of a variety of subjective and objective factors, the departing from the original is objective. On purpose or not, some original thoughts of the writer are changed. The initiative of the translator is not the target to make pursuit and efforts, but the objective description of reality. Sometimes, the translator has to take advantage of the nonequivalent translation--initiative translation.

Many successful examples from translation practice justify that the initiative translation is a kind of appreciation. Because it not only gives the source text a new appearance, but also can attract a wider range of readers by its new literature communication. It extends the work's life, and gives it a second life. An appreciation work is the discovery of the new value, reasoning, and judgment. Initiative translation just starts at where a particular language has referred to. To make the appreciation, first of all, one must go beyond the original author and the original readers' existing understanding and give a new evaluation.

Although more and more people admit that translation is an initiative activity, and the absolute faithfulness is difficult to achieve. But that doesn't mean faithfulness can be given up while the 
pursuit of initiative should be advocated. Initiative is limited by the text, at the same time, it tries to go beyond the text. We should grasp the initiative limits correctly to reach the translation purpose and achieve good literature, cultural and social effects. The translator does not have the writer's initiative freedom, he must try to control himself, combined with the writer as far as possible, making his own translation in accordance with the intention of the author and the original style, neither free embellish nor corners cutting is allowed. The translator should use initiative and grasp the initiative limit, to prevent the original out of tune.

As the field of translation study broaden from the transformation of the two languages to the role of the translator in the translation process, the research about initiative has become an important topic in translation studies. Translators' initiative divided into two categories, the conscious and the unconscious, embodied in (1) personalized translation, including domestication and foreignization;(2) mistranslation and omission; (3) partially translation and compilation (4) conversion and adaptation.

\section{Subjective Factors Restricting the Translator's Initiative}

\section{The translator's life experience}

In $283 \mathrm{AD}$, the western most famous Roman translator St.Jerome chaired the Latin Bible translation. He was born in Strideon, Dalmatia province of the Roman empire, and his parents were Christian. Jerome had been living in Rome since an early age, being exposed to accept education from philosophers and speakers. In $360 \mathrm{AD}$, he accepted the baptism of the Pope Liberuius, and became a Christian. Jerome received a good education since he was young. When traveling in Asia minor, he studied theology. He had deep knowledge of the Latin and Hebrew language. 282 AD, for Jerome, at the same time, for the western Christian world, is a landmark. In that year the Pope Damascus in Rome summoned Jerome, suggested him to translate Hebrew bible into Greek (Jerome is actually the Pope's good friend and adviser). Jerome had been living in the Palestinian for more than 30 years, and finally settled in Bethlehem. A lifelong commitment to the spread of Christianity and the Bible translation. Jerome died in September, 420 AD. Thanks to his great contribution to translation, the western formally put each year on September 30 “Translation Day”.

Kumarajiva is an ancient famous translator of China. His ancestors were from Tianzhu (India), but he was born in the western regions- Qiuci (now the Xinjiang kuqa area), so he was familiar with Sanskrit since childhood. When he was in his teenage years, he was famous for mastering of Buddhist scriptures. FuJian promised the request of Dao An and welcomed Kumarajiva to China to translate. But FuJian was killed, Kumarajiva lived in liangzhou for fifteen or sixteen years. He gradually became familiar with and be master of Chinese. That made preparation for his future translation. In 401, Yao Xing invited Kumarajiva to Chang'an. Kumarajiva started to translate Buddhist scriptures. He is the first one to introduce Indian Buddhism by what it was. and he played an important role in the initiate of free translation.

Life experience can't be forecast, copied or arranged. The family background, education, the living experience in different language areas or the support from the sponsor is very important in making a great translator , just as the old saying goes: “Great moment makes great man.”.

\section{The Translation Thoughts of the Translator}

It is about the translator's choice. It is the greatest contribution in the western literary translation that Ezra Loomis Pound opened a new way beyond the literal translation and free translation--interpretative translation. In pound's eyes, translation should combine with initiative. Translation is creation. Translating a poem is creating a poem. Poet, gain inspiration from the original, then reprocess. Translation is no longer a calculation of syllable and meaning equivalence. The translator make decision to display his own thoughts and express his insight.

Vladimir Nabokov is a representative of absolutely literal translation. He said: "The clumsiest literal translation is a thousand times more useful than the prettiest paraphrase." In his eyes, "likeness in spirit" is a betrayal of the source text and the writer. Only literal translation can be called translation. He hold the opposite thoughts compared with Pound. 
Traditionally, male translators tend to use "father" instead of "parent", "brother" instead of "brother or sister", the trace of women was quietly erased in the daily discourse and translation. At the same time, the feminist translation tries to reveal the features of female gender and translation subjectivity.

The translation thoughts of the translator lead to different translation with different style, determining whether the translation will be faithful enough and which word the translator will choose.

\section{The Translator's Ability}

During the translation of the source text, the translator need to utilize their own cultural knowledge , language skills and the ability to deal with the source text.

Cultural knowledge: In order to accurately convey the source culture to the readers, translators need to make sure he has his own full understanding of the source and target language culture.

Translator's language skills: During translation, the translator must pay attention to the difference between English and Chinese syntactic structure, having the ability to find out the relationship between clauses.

Translator's ability to deal with the source text: Translators should not only convey semantic information of the source text, but should also convey the style, culture and aesthetic information. Literary works will use some rhetorical devices to produce specific effects and then realize the literary value, but because there is a huge difference between two languages, it is difficult to find equivalent expression between the semantic and pragmatic meaning, in this case, the translator must play their initiative and imagination.

\section{Objective Factors Restricting the Translator's Initiative}

\section{The Source Text}

"The initiative of reading can only be free in the given conditions, can only be imagined under the guidance of the source text."(Jin Yuanpu, 1997:165). That is to say, the translator can't follow his inclinations to explain the source text. Although different readers can have different understandings to the same text, this kind of "different" is restricted by the text itself. As a result, "Lin Daiyu won't become Jia Baoyu, and Hamlet won't become Romeo."( Ma Xiao, 2000)

\section{Culture}

"Translation is not only to convey semantic information, but should also convey cultural, pragmatic and aesthetic information, rhetoric, etc.”(Zhou Fangzhu, 2004:246-247). The translator in literary translation should not only convey the content of the original text, but should convey the cultural and aesthetic information at the same time. In fact, literary translation should be regarded as a kind of cultural interaction, and the translator should contribute to the cultural interaction. The problem is that whether readers can accept different culture with different cultural background.

\section{Reader's Expectation}

The same as the translator, the readers have their own expectations. Before the translation, translators must take potential readers into consideration and make the translation accepted by readers both in the language and cultural level.

A literature can arouse readers' memories about the past, and lead him into a particular experience and reminded him of a certain expectation. Therefore, reading stimulates or changes the readers' horizon of expectation, repositions the expectation, or implement some expectations. Because every reader is different from others in talent, experience and personal accomplishment, so literary will show every reader different contents and meanings. In addition, the readers from different times will have different understanding on the same piece of literature, as a western proverb says, "There are one thousand readers, while there are one thousand Hamlet." The meaning of literary works is given by the work itself and readers, and the translator is the first reader of the source text. 


\section{The Sponsor}

Andre Lefevere regards the literature translation and other form of rewriting as a system. The literature system is controlled by dual factors, one is the internal literature factors, consisting of all kinds of professionals such as critics, reviewers, teachers and translators; The other is "sponsor", who works out of the system, usually is more interested in the literature ideology than literary poetic, to promote or prevent literature reading, writing, or rewriting, and there are various kinds of power (or institution), such as religious group, class, government departments, press institutions, mass media, or individual.

\section{Social Dominating Ideology.}

Ideology refers to the system that reflects the specific economic form, the interests and requirements of a specific class or social group. Its basic content includes people's views about politics, law, ethics, philosophy, art, religion and so on. The social nature of literary determined that translation should serve the particular ideology, the translation cannot rival the ideology. Social dominating ideology is accepted by most readers, for example, in the late Qing dynasty, the classical writings in classical style is one of the main literary style in formal writing and translation, so in order to attract more readers, Lin Shu adopted the classical style in the translation.

\section{Summary}

Translator's initiative is unavoidable and even indispensable in translation. But the translator's initiative cannot be executed arbitrarily. The translator's initiative is restricted by subjective factors, including the translator's life experience, the translation thoughts of the translator, and the translator's ability (the ability embodied in three aspects: cultural knowledge, language skills and the ability to deal with the source text). And the objective factors also restrict the translator's initiative to a great extent, which can be divided into five parts: the source text, culture, reader's expectation, the sponsor and social dominating ideology.

Translating the original can as well as be a means of resistance and creation. There is no denying that during the translation, everywhere of the translation embodies the initiative of the translator. The presence or absence of the initiative, strong or weak, directly influences the whole translation process, and affects the result of the translation, namely the value of the translation.

The translator is a member of society, so he has his own special life experience, ability and translation thoughts. The support from the sponsor is important. Meanwhile, the translator has the right to choose whether adapting or resisting the social dominating ideology. To make the most of the translator's initiative, Specifically, at first, before the translation, the translator must thoroughly understand the source text, digging out the real meaning of which the source text wants to convey; Secondly, the translator should spare no effort to improve the readers' acceptance, deepen the readers' understanding of the source, and meet the readers' expectation. At last, the translator should constantly improve his ability in language, culture and dealing with the source text.

\section{References}

[1] Bassnett, Susan \& Andre Lefevere. Constructing Cultures: Essays on Literary $\quad$ Translation[M]. Clevedon: Multilingual Matters, 2000.

[2] Eoyang, Eugene Chen. The Transparent Eye: Reflection on Translation, Chinese Literature, and Comparative Poetics[M].Honolulu: Shaps Library of Translation,1993.

[3] Hawkes, David. The Story of the Stone[M]. New York: Penguin Books, 1973.

[4] Lefevere A. Translation, Rewriting and the Manipulation of Literary Fame [M]. London\&New York: Routledge, 1992.

[5] Shakespeare. Romeo and Juliet[M]. New York: Bantam Classics, 1988. 